\title{
ANALISIS PENDAPATAN PETANI PADI PENGGUNA PUPUK ORGANIK DAN ANORGANIK DI KECAMATAN HARAU
}

\author{
Riva Hendriani ${ }^{1}$, Sri Kembaryanti Putri ${ }^{2}$, Latifa Hanum ${ }^{1}$, dan Mukhlis ${ }^{1}$ \\ ${ }^{1}$ Program Studi Agribisnis Pertanian, Politeknik Pertanian Negeri Payakumbuh \\ ${ }^{2}$ Program Studi Teknologi Pangan, Politeknik Pertanian Negeri Payakumbuh \\ Jl. Raya Negara Km. 7 Tanjung Pati, 26271, Payakumbuh \\ Korespondensi:holy_man76@yahoo.com
}

$\begin{array}{ll}\text { Diterima } & : 25 \text { Februari } 2018 \\ \text { Disetujui } & : 26 \text { Maret } 2018 \\ \text { Diterbitkan } & : 15 \text { Juli } 2018\end{array}$

\begin{abstract}
ABSTRAK
Penelitian ini didasarkan pada: ketergantungan petani yang menggunakan pupuk anorganik dan meningkatkan harga pupuk anorganik yang berakibat pada peningkatan biaya produksi dan berkurangnya keuntungan usahatani padi, sehingga mempengaruhi kesejahteraan petani keluarga. Tujuan penelitian ini adalah: 1) Untuk mengetahui pendapatan petani padi, 2) Untuk mengetahui perbedaan pendapatan antara petani pupuk organik padi dan pupuk petani padi anorganik. Metode pencapaian tujuan dilakukan dengan: analisis usahatani menggunakan rumus pendapatan usahatani. Hasil penelitian menunjukkan bahwa: 1) Pendapatan petani padi pupuk organik adalah Rp.657.838 menjadi 14.633.798; pendapatan rata-rata sebesar Rp. 5.464.104,03. Sedangkan pendapatan petani padi pupuk anorganik adalah Rp. 500.983 hingga Rp 14.189.743; pendapatan rata-rata sebesar Rp $5.901 .806,24$; 2) Pendapatan petani padi pupuk organik tidak berbeda nyata dengan pendapatan petani padi anorganik.
\end{abstract}

\section{Keywords: Analisis, Penghasilan, Petani Padi, Organik, Anorganik}

\begin{abstract}
This research is based on: the dependence of farmers using inorganic fertilizers and increase the price of inorganic fertilizers that result in increasing production costs and reduced profits of rice farming, thus affecting the welfare of family farmers. The purpose of this research are: 1) To determine the income of rice farmers, 2) To know the difference of income between organic fertilizer rice farmers and inorganic rice farmers fertilizer. The method of achieving the goal is done by: analysis using the formula of farm income. The results showed that: 1) The income of organic fertilizer rice farmers is IDR 657,838 to 14,633,798; average income of IDR 5.464.104,03. While the income of inorganic fertilizer rice farmers is IDR 500.983 to $R p$ 14.189.743; average income of IDR $5.901 .806,24 ; 2)$ The income of organic fertilizer rice farmers did not differ significantly with income of inorganic fertilizer rice farmers.
\end{abstract}

Keywords: Analysis, Income, Rice Farmers, Organic, Inorganic 


\section{I.UMIBUNG}

\section{(1)}

\section{PENDAHULUAN}

Tanaman padi merupakan salah satu komoditi yang mempunyai prospek cerah guna menambah pendapatan para petani. Hal tersebut dapat memberi motivasi tersendiri bagi petani untuk lebih mengembangkan dan meningkatkan produksinya dengan harapan agar pada saat panen usaha memperoleh hasil penjualan tinggi guna memenuhi kebutuhannya. Namun kadang kala dalam kenyataannya berbicara lain, ketika saat panen tiba hasil melimpah tetapi harga mendadak turun, dan lebih parah lagi jika hasil produksi yang telah diprediksikan jauh melenceng dari jumlah produksi yang dihasilkan, produksi minim, harga rendah dan tidak menentu membuat petani padi kadang merasa kecewa bahkan patah semngat untuk tetap megembangkan usaha pertaniannya.

Penggunaan pupuk anorganik (kimia buatan) menjadi bagian yang tak terpisahkan dari sistem pertanian modern. Dalam beberapa dekade terakhir, penggunaan pupuk buatan dan input buatan pabrik yang lain cenderung meningkat secara signifikan, namun demikian, peningkatan tersebut juga disertai dengan peningkatan beberapa problema, antara lain tekanan inflasi, degradasi ekosistem pertanian serta ancaman kerusakan lingkungan dan kesehatan manusia (Salikin, 2003). Agar tidak terjadi keadaan yang lebih buruk lagi, yang dapat mengganggu keberlanjutan sistem produksi padi sawah, maka perlu ditempuh upaya-upaya guna mengkonservasi dan merehabilitasi sumberdaya lahan yang ada, terutama lahan sawah. Salah satu upaya yang dapat ditempuh oleh petani untuk memperbaiki kondisi tersebut adalah petani padi kembali menggunakan pupuk organik pada usahatani padi sawah. Kenaikan harga dan kelangkaan pupuk kimia menjadi salah satu penyebab berkurangnya pendapatan petani dan turunnya kesejahteraan petani.

Dikembangkannya solusi teknologi usahatani padi organik untuk mengatasi permasalahan pupuk anorganik terutama masalah kenaikan harga pupuk anorganik maka hal ini telah menyebabkan sebagian kecil petani padi di Kabupaten Lima Puluh Kota, telah mulai menggunakan teknologi pertanian organik dengan pupuk utama menggunakan pupuk kandang atau kotoran hewan lainnya untuk menekan biaya produksi usahatani padi.

Permasalahan dalam penelitian ini adalah: 1) Seberapa besar jumlah pendapatan petani padi pengguna pupuk organik dengan petani padi pengguna pupuk anorganik, 2) 
Adakah perbedaan pendapat anantara petani padi pengguna pupuk organik dengan petani padi pengguna pupuk anorganik. Sehingga tujuan dari penelitian ini adalah: 1) Untuk menentukan jumlah pendapatan petani padi pengguna pupuk organik dengan petani padi pengguna pupukan organik, 2) Untuk mengetahui perbedaan pendapatan antara petani padi pengguna pupuk organik dengan petani padi pengguna pupuk anorganik.

\section{METODE PENELITIAN}

Penelitian dilakukan di Kecamatan Harau Kabupaten Lima Puluh Kota. Penelitian ini dilakukan selama lebih kurang 8 bulan, mulai bulan April 2017 sampai bulan November 2017.

Penelitian ini menggunakan survey dengan tanya jawab langsung kepada petani di daerah penelitian. Metode survey pada umumnya merupakan cara pengumpulan data dari sejumlah unit atau individu dalam jangka waktu tertentu. Dengan metode survey ini memungkinkan mendapatkan data yang memberikan gambaran secara umum tentang topik yang sedang diteliti (Singarimbun, 2011).

Pemilihan daerah penelitian dilakukan dengan cara purposive methode atau sengaja (Sugiyono, 2013). Terpilih dua Nagari yaitu Nagari Taram dan Nagari Sarilamak dengan dasar pertimbangan :

1. Nagari terpilih merupakan sentra produksi padi di Kecamatan Harau.

2. Nagari terpilih belum pernah diadakan penelitian tentang analisis pendapatan petani padi pengguna pupuk organik dan pupuk anorganik.

Untuk menjawab tujuan penelitian diperlukan adanya sampling. Menurut Singarimbun (2011), terdapat empat faktor yang harus dipertimbangkan dalam menentukan sampel dalam suatu penelitian yaitu :

1. Derajat keseragaman dari populasi, semakin seragam populasi itu, semakin kecil sampel yang dapat diambil.

2. Presisi yang dikehendaki dari penelitian, dimana makin tinggi tingkat presisi yang dikehendaki, makin besar sampel yang harus diambil.

3. Rencana analisa, dimana besar kecilnya jumlah sampel disesuaikan dengan rencana analisa yang dipakai, semakin rumit perhitungan statistik yang dipakai dan atau 


\section{I.UMIBUNC}

semakin banyak strata yang ditetapkan, biasanya semakin banyak sampel yang diperlukan.

Pengambilan sampel (Sampling Methode) menggunakan metode pengambil-an sampel bola salju (Snowball Sampling Methode). Menurut Rianse dan Abdi (2008), metode sampling bola salju digunakan apabila tidak tersedianya data jumlah populasi sehingga tidak dimungkinkan untuk membuat kerangka sampel. Dengan metode ini, mula-mula peneliti mencari responden yang sesuai dengan kriteria yang ditetapkan, kemudian dari responden ini akan menunjuk atau mengajak temannya yang lain untuk dijadikan sampel, dan seterusnya sampai jumlah sampel yang dianggap peneliti sudah mewakili secara representatif untuk menjawab tujuan penelitian. Adapun total jumlah sampel penelitian adalah 80 petani padi sawah pengguna pupuk organik dan anorganik.

Data yang dikumpulkan dalam penelitian ini adalah: 1) Data primer diperoleh dari petani responden atau petani sampel dengan melalui metode wawancara berdasarkan daftar pertanyaan/kuisioner yang telah disiapkan terlebih dahulu. 2) Data sekunder diperoleh dari berbagai instansi yang ada kaitannya dengan penelitian ini, disamping itu juga informasi dari berbagai pihak.

Untuk mengetahui jumlah pendapatan usahatani jagung pipilan, dilakukan analisa usaha tani menggunakan rumus pendapatan usahatani. Secara matematis dapat ditulis sebagai berikut:

$$
\mathrm{Pd}=\mathrm{TR}-\mathrm{TC}
$$

Dimana: $P d=$ Pendapatan Usaha Tani

$$
\begin{aligned}
& \mathrm{TR}=\text { Total Penerimaan } \\
& \mathrm{TC}=\text { Total Biaya }
\end{aligned}
$$

Untuk mengetahui perbedaan pendapatan antara petani padi pengguna pupuk anorganik dengan petani padi pengguna pupuk organik digunakan Uji t-student dengan formulasi sebagai berikut (Sugiyono, 2013a):

$$
\mathrm{t}_{\text {hitung }}=\frac{\bar{x}_{1}-\bar{x}_{2}}{\sqrt{\frac{\left(n_{1}-1\right) s_{1}^{2}+\left(n_{2}-1\right) s_{2}^{2}}{n_{1}+n_{2}-2}} \sqrt{\frac{1}{n_{1}}+\frac{1}{n_{2}}}}
$$

dimana :

$$
\mathrm{t}=\text { Nilai t hitung }
$$




\section{I.UMIBUNC}

$\bar{X}_{1}$ dan $\bar{X}_{2}=$ Harga rata-rata sampel yang diperbandingkan

$\mathrm{S}_{1}$ dan $\mathrm{S}_{2}=$ Standart deviasi yang diperbandingkan

$\mathrm{n}_{1}$ dan $\mathrm{n}_{2} \quad=\quad$ Besar sampel yang diperbandingkan

Kriteria pengambilan sampel :

1. $\mathrm{t}$ hitung $>\mathrm{t}$ tabel, berarti ada beda nyata antara nilai rata-rata yang diperbandingkan.

2. $\mathrm{t}$ hitung $<\mathrm{t}$ tabel, berarti tidak ada beda nyata antara nilai rata-rata yang diperbandingkan.

\section{HASIL DAN PEMBAHASAN}

\section{Jumlah pendapatan petani padi}

Berdasarkan data primer yang diperoleh dari hasil survey, tabulasi dan pengolahan data, dapat diperoleh: Jumlah Pendapatan petani padi pengguna pupuk organik adalah Rp 657.838 - Rp 14.633.798; dengan rata-rata pendapatan petani sebesar Rp 5.464.104,03. Untuk lebih jelas menjadi dilihat pada Tabel 1.

Tabel 1. Jumlah dan rata-rata jumlah pendapatan petani padi pengguna pupuk organik di Kecamatan Harau

\begin{tabular}{rclllr}
\hline No & Pendapatan & No & Pendapatan & No & Pendapatan \\
\hline 1 & 6.467 .832 & 15 & 2.778 .973 & 29 & 5.030 .450 \\
2 & 2.907 .444 & 16 & 2.362 .965 & 30 & 6.738 .867 \\
3 & 4.615 .967 & 17 & 3.549 .922 & 31 & 5.698 .922 \\
4 & 1.161 .994 & 18 & 4.867 .931 & 32 & 920.466 \\
5 & 8.709 .865 & 19 & 885.468 & 33 & 1.806 .982 \\
6 & 14.633 .798 & 20 & 3.120 .449 & 34 & 18.674 .816 \\
7 & 4.069 .936 & 21 & 2.072 .456 & 35 & 19.020 .788 \\
8 & 10.992 .882 & 22 & 1.752 .956 & 36 & 8.282 .402 \\
9 & 2.484 .974 & 23 & 3.361 .420 & 37 & 18.811 .813 \\
10 & 1.563 .458 & 24 & 4.831 .930 & 38 & 8.642 .399 \\
11 & 1.069 .968 & 25 & 3.882 .940 & 39 & 8.239 .900 \\
12 & 1.475 .963 & 26 & 3.393 .954 & 40 & 5.743 .708 \\
13 & 657.838 & 27 & 4.759 .928 & & \\
14 & 4.518 .970 & 28 & 4.000 .466 & $\overline{\mathbf{y}}$ & $\mathbf{5 . 4 6 4 . 1 0 4 , 0 3}$ \\
\hline
\end{tabular}

Jumlah Pendapatan petani padi pengguna pupuk anorganik adalah Rp 500.983 Rp 14.189.743; dengan rata-rata pendapatan petani sebesar Rp 5.901.806,24. Untuk lebih jelas dapat dilihat pada Tabel 2. 


\section{I.UMIBUNG}

Tabel 2. Jumlah dan rata-rata jumlah pendapatan petani padi pengguna pupuk anorganik di Kecamatan Harau

\begin{tabular}{rrrrrr}
\hline No & Pendapatan & No & Pendapatan & No & Pendapatan \\
\hline 1 & 6.189 .952 & 15 & 5.562 .453 & 29 & 6.779 .922 \\
2 & 6.219 .922 & 16 & 9.709 .907 & 30 & 5.664 .965 \\
3 & 14.189 .743 & 17 & 6.251 .952 & 31 & 7.014 .908 \\
4 & 11.689 .918 & 18 & 1.884 .825 & 32 & 5.025 .897 \\
5 & 6.537 .437 & 19 & 2.798 .924 & 33 & 2.829 .944 \\
6 & 6.729 .921 & 20 & 964.434 & 34 & 2.993 .946 \\
7 & 1.889 .966 & 21 & 1.851 .957 & 35 & 2.544 .957 \\
8 & 10.498 .878 & 22 & 2.067 .937 & 36 & 5.112 .443 \\
9 & 2.323 .966 & 23 & 449.954 & 37 & 2.254 .954 \\
10 & 2.319 .960 & 24 & 9.723 .948 & 38 & 7.967 .405 \\
11 & 500.983 & 25 & 2.257 .460 & 39 & 20.323 .174 \\
12 & 9.422 .451 & 26 & 1.599 .460 & 40 & 17.637 .291 \\
13 & 10.332 .405 & 27 & 7.729 .866 & & \\
14 & 5.104 .923 & 28 & 3.118 .945 & $\overline{\mathbf{y}}$ & $\mathbf{5 . 9 0 1 . 8 0 6 , 2 4}$ \\
\hline
\end{tabular}

Perbedaan pendapatan petani padi pengguna pupuk organik dengan petani padi pengguna pupuk anorganik

Analisis pendapatan petani inid ilakukan dengan menggunakan analisis usahatani secara tabulasi. Pendapatan tertinggi yang diperoleh oleh petani padi pengguna pupuk anorganik adalah Rp 24.324.000,00 pada luasan 1,4 hektar dan pendapatan terendah adalah $\mathrm{Rp} 501.000,00$ pada luasan 0,06 hektar. Sedangkan pendapatan yang diperoleh oleh petani padi pengguna pupuk organik adalah Rp 19.021.000,00 pada luasan 1,1 hektar dan pendapatan terendah adalah $\mathrm{Rp} 658.000,00$ pada luasan 0,08 hektar. Untuk lebih jelas dapat dilihat pada Tabel 3.

Analisis perbedaan rata-rata pendapatan antara petani padi pengguna pupuk organik dengan pengguna pupuk anorganik menggunakan uji $t$ student. Rata-rata pendapatan petani padi anorganik adalah $\mathrm{Rp}$ 5.901.900,00; sedangkan rata-rata pendapatan petani padi organik adalah Rp 5.464.182,50. Untuk lebih jelasnya tentang hasil uji t student dapat dilihat pada Tabel 3. 


\section{I.UMIBUNG}

ISSN 1412-1948

Tabel 3. Uji t Student rata-rata pendapatan antara petani padi pengguna pupuk organik dengan petani padi pengguna pupuk anorganik

\begin{tabular}{lccc}
\hline \multicolumn{1}{c}{ Status PetaniPadi } & $\begin{array}{c}\text { Rata-rata PendapatanPetanipadi } \\
\text { (1 kali musimtanam })\end{array}$ & t hitung & t tabel \\
\hline Organik & $\begin{array}{l}\text { Rp5.901.900,00 } \\
\text { Anorganik }\end{array}$ & $\mathbf{0 , 4 4}$ & $\mathbf{1 , 6 6 5}$ \\
\hline
\end{tabular}

*) Nyata perhitungan pada taraf nyata $5 \%$

Berdasarkan Tabel 3, terlihat rata-rata pendapatan petani padi antara petani padi pengguna pupuk organik dengan petani padi pengguna pupuk anorganik setelah diuji secara statistik menunjukkan perbedaan yang tidak nyata. Hal ini berarti bahwa petani padi pengguna pupuk organik memperoleh rata-rata pendapatan yang tidak berbeda signifikan atau hampir sama dengan pendapatan petani padi pengguna pupuk anorganik.

Hal ini terjadi karena penggunaan pupuk organik dalam usahatani padi masih belum mampu meningkatkan produksi padi secara signifikan, akibatnya produksi padi yang menggunakan pupuk organik tidak jauh berbeda dengan produksi padi yang menggunakan pupuk anorganik. Kondisi ini terlihat jelas dari data hasil survey yang menunjukkan bahwa rata-rata produksi padi petani pengguna pupuk organik tidak berbeda secara signifikan atau sama dengan produksi dari petani padi pengguna pupuk anorganik.

\section{KESIMPULAN}

1. Pendapatan petani padi pengguna pupuk organik adalah Rp 657.838 - Rp 14.633.798; pendapatan rata-rata sebesar Rp 5.464.104,03. Sedangkan Pendapatan petani padi pengguna pupuk anorganik adalah Rp 500.983 - Rp 14.189.743; pendapatan rata-rata sebesar $\mathrm{Rp} 5.901 .806,24$.

2. Pendapatan petani padi pengguna pupuk organik tidak berbeda secara nyata dengan petani padi pengguna pupuk anorganik. 


\section{REFERENSI}

Ariani, Mewa. 2002. Penawaran dan Permintaan Komoditas Kacang-kacangan dan Umbi-umbian di Indonesia. Pusat Penelitian dan Pengembangan Sosial Ekonomi Pertanian. Bogor.

Badan Pusat Statistik Kabupaten Lima Puluh Kota. 2015. Kabupaten Lima Puluh Kota dalam Angka. Sarilamak.

Dinas Tanaman Pangan dan Hortikultura Kabupaten Lima Puluh Kota, 2009. Laporan Tahunan 2015. Harau.

Hernanto, Fadholi. 1993. Ilmu usaha tani. Institut Pertanian Bogor. Bogor.

Rahim, Abd. Dan Hastuti, Diah Retno Dwi. 2008. Pengantar, Teori dan Kasus Ekonomika Pertanian. Penebar Swadaya. Jakarta.

Rianse, Usman dan Abdi. 2008. Metodologi Penelitian Sosial dan Ekonomi-Teori dan Aplikasi. Penerbit Alfabeta. Bandung.

Salikin, K.A, 2003. Sistem Pertanian Berkelanjutan. Kanisius, Yogyakarta.

Singarimbun M, 2011. Metode Penelitian Survei. Lembaga Penelitian. Pendidikan dan Penerangan Ekonomi dan Sosial. Jakarta.

Soekartawi. 2002. Analisis Usahatani.Universitas Indonesia. Jakarta. Jakarta.

2003. Teori Ekonomi Produksi (Dengan Pokok Bahasan Analisis Fungsi Cobb-Douglas). PT. Raja Grapindo Persada. Jakarta

Suratiyah, Ken. 2008. Ilmu Usahatani. Penebar Swadaya. Jakarta.

Sutanto, Rahman. 2002. Pertanian Organik. Menuju Pertanian Alternatif dan Berkelanjutan. Kanisus. Yogyakarta.

Su’ud, Hassan. 2007. Pengantar Ilmu Pertanian. Yayasan Pena. Banda Aceh.

Sugiyono, 2013a. Statistika Untuk Penelitian. Alfabeta. Bandung.

Sugiyono. 2013b. Metode Penelitian Kuantitatif dan Kualitatif dan R \& D. Alfabeta. Bandung.

Syahyuti. 2006. 30 Konsep Penting dalam Pembangunan Pedesaan dan Pertanian. Penerbit PT. Bina Rena Pariwara. Jakarta.

Tjakrawiralaksana, A. 1996. Usahatani. Institut Pertanian Bogor. Bogor.

Wirartha, I Made. 2006. Metode Penelitian Sosial Ekonomi. Penerbit CV Andi Offset. Yogyakarta 